\title{
"3+3+3" Mode: Research on International Training Path of Graduate Students
}

\author{
Wang Jingnan ${ }^{1, a}$ \\ ${ }^{1}$ School of Economics, Capital University of Economics and Business, Zhangjialukou-121, Fengtai District,Beijing,China \\ awangjingnan@cueb.edu.cn
}

\begin{abstract}
With the development of economic globalization, the demand for high-end talents in various fields is increasing, and the international training of postgraduates has gradually become the focus of talent training and in the development of universities. Based on the analysis of the problems existing in the internationalization of postgraduate education and on the thinking of how to better train international talents, this paper sums up the " $3+3+3$ " mode training path in universities, which is guaranteed by the reform of curriculum system, the construction of communication platform and the improvement of service policies, so as to provide reference for the cultivation of international talents to meet the development requirements of the times.
\end{abstract}

Keywords: postgraduate, education, internationalization

\section{“3+3+3” 模式: 研究生国际化培养路径研究}

王璟楠 ${ }^{1,}$

\footnotetext{
${ }^{1}$ 首都经济贸易大学经济学院, 张家路口 121 号, 丰台区, 北京市, 中国

awangjingnan@cueb.edu.cn
}

\section{摘要}

随着经济全球化的发展, 各领域对高端人才的需求量不断上升, 研究生国际化培养逐渐成为高校人才 培养发展的重心。本文通过分析研究生教育国际化存在的问题, 以如何更好的培养国际化人才为思路, 总结了高校以改革课程体系、构筑交流平台及完善服务政策为保障的 “ $3+3+3$ ” 模式培养路径, 进而为 培养适应时代发展要求的国际化人才提供借鉴。

关键词: 研究生、教育、国际化

\section{1. 前言}

伴随经济全球化程度的不断加深, 国家综合竞争力 的提高已转化为对国际高素质人才的滋滋不倦需求。而 在国际高素质人才的培养过程中, 研究生的国际化培养 具有重要的意义。面临中国综合国力的提高, 出国接受 教育已不如往日般热络, 更多中国学生选择在国内进行 研究生生涯。这就对国内的研究生国际化培养工作提出 了重大挑战。研究生培养国际化就是要以国际一流大学、 一流学科为标杆, 制定与国际接轨的培养方案、课程体 系、教学模式。本文通过对当前研究生国际化培养路径 的现存问题进行剖析, 从而提出相应的改革方案, 最终 目的即是通过对研究生国际化培养路径与方式的革新, 达到使学生具备完整的国际化知识能力, 以及具有处理 国际化问题实践水平, 真真正正的为我国培养建设一批 高质量国际化人才。

\section{2. 研究生教育国际化存在的主要问题}

目前研究生国际化教育队伍不断地在发展壮大。虽 然各大高校在研究生国际化培养过程中做了一定的调 整, 但在当前教育国际化背景下, 我国研究生国际化培 养尚存在着部分问题, 主要体现在以下几个方面。

\section{1. 研究生国际化培养方式有待提开}

首先, 研究生国际化培养目标定位不清晰。高校更 注重研究生的理论知识培养, 而忽视了研究生对国际学 术视野、国际学术思维以及国际学术交流实践能力的培 养 ${ }^{1}$ 。其次, 研究生国际化课程设置不完善。目前各大高 校的研究生课程培养方案较为单一，部分教师授课采用 多年陈旧的课件，教授学生的思路也无法跟上国际的发 展, 缺乏创新和先进性。加上高校研究生培养方案中课 
程设定中选修课的不足, 造成研究生课程缺乏广泛度, 这些情况不利于研究生教育国际化的培养。再次, 研究 生课堂教学模式较为单一, 部分高校仍然采用与本科生 授课方式相同的课堂讲授模式, 这使得研究生在培养过 程中缺少了自主思考的过程以及实践的过程, 考核评价 模式也较单一。

\section{2. 研究生国际化交流缺少平台}

目前大部分高校的研究生国际培养方式采用 “请进 来, 送出去” 的方式, 即学校定期聘请少量的国外知名 教授来校进行讲座, 招收、选派少量的研究生进行国际 交流培养 ${ }^{2}$, 在这种模式下, 各大高校缺少国际化交流 的平台, 现有的模式成本高、受众面小, 不利于研究生 国际化的培养, 并且在缺乏交流平台的情况下, 不利于 培养自身国际化的师资队伍。研究生的国际化培养决不 能简单等同于将学生送到境外进行学习, 不能因国外资 源的优势而忽略国内培养的具有的根本性基础性意义。 换言之, 放弃了我们自己培养能力, 就是放弃了研究生 国际化培养的原本目的。所以, 如何立足国内, 发展与 国际接轨的培养方案、课程体系、教学模式, 是建设国 际一流大学、一流学科的重要考评依据, 也是衡量研究 生国际化培养成功与否的标杆。这需要研究生培养创新 模式的革新, 建立健全对外交流平台, 实现如何更好地 教书育人，而不仅仅是 “送出国境” 这种表面文章。

\section{3. 研究生国际化交流缺少保障}

研究生国际化培养事业, 依赖于完善的体系保障。 我国当前体系虽有部分措施制度已经落实, 然而还缺乏 统一的保障措施实施纲领, 对于研究生教育国际合作学 校办学质量评估和保障机制, 还没有提出具体要求和监 管实施方案。其次, 尚未建成系统化的师资与课程力量。 优秀称职的教师队伍是建设研究生国际化培养目标的 物质基础。鉴于我国当前师资队伍力量尚不能完全满足 国际化培养的需求, 存在问题主要是师资人员的国际化 程度不足。这体现在外国优秀教育人员来华参与研究生 培养工作还未形成趋势, 国内教师人员的国际化语言水 平整体有限, 国内教职人员的国际化教育背景普遍不高。 因此, 培养国际化的研究生, 首先需要提高教师队伍的 国际化水平。最后，未能形成法制化的规范制度保障战 略规划的实现, 建立健全完整的体系保障制度集群, 是 函待解决的现实问题。因此需要对比国际上通行保障体 系, 找出差距, 看清方向, 以实现研究生国际化培养保 障系统的弯道超车。

\section{3. 研究生国际化培养 “ $3+3+3$ ” 模式的内 涵界定}

研究生际化培养 “ $3+3+3$ ” 模式是指按照从国际学术
视野、国际学术思维、国际学术交流等国际化能力的多 元内涵出发, 通过改革 3 层次的课程体系、建立立体 化的 3 类交流平台、实施全方位的 3 类保障扶持政策 构筑起研究生国际化培养体系, 达到 “创新能力强、学 术思维广、国际化能力高” 的水平。3 层次的课程体系 是指第一层针对低年级学生的英文讲座课程, 第二层为 针对高年级的全英文课程, 第三层为针对具备出国意愿 学生开设的外国专家课程; 3 类交流平台是指国际学术 会议、暑期国际学校交流、双学位交流；3 类保障措施 完善国际化教育政策法规和体制机制、加强师资队伍国 际化、加强系统化监督管理

\section{4. 基于 “ $3+3+3$ ” 模式研究生国际化培 养的实践路径}

研究生国际化培养是指在研究生的课程学习、论文 工作与实践交流等环节中采用国际合作手段进行培养 的一种方式 ${ }^{3}$ 。其目标是利用国际中优秀教育教学资源, 培养具有国际化视野, 熟练使用国际规则, 可达到国家 对外开放标准, 能够完成国际竞争的高层次人才。

\section{1. 改革分层次的课程体系实现研究生教学 国际化}

在考虑如何推进研究生国际化培养水平的问题时, 相关课程体系的建设是至关重要的。没有良好的，有效 的课程安排, 研究所国际化培养将失去实质性的依托, 成为 “无根之木, 无源之水”。因此, 研究生课程建设必 须面向学科前沿、面向国际一流、面向国家需求, 课程 教学目标应以坚实基础、紧跟学科前沿、朝着国际视野 多元化方向发展为理念 ${ }^{4}$ 。研究生教学安排将课程分为 3 个层次, 根据循序渐进的原则, 不断探索多样性的教 学模式, 为研究生架构一个完整的国际化体系, 以适应 教育国际化的多方面的融合。

首先是设置包括适合低年级的英文专题系列讲座, 邀请国际合作学院的外教教师参加讲座互动, 启迪研究 生的思维和认识, 在讲座中加入视频演示、老师与学生 互动的教学环节, 在讲座过程中采用问题探究型的教学 模式, 让研究生能积极地参与到课堂当中来, 激发研究 生在学习中的国际性思维, 培养学生合理运用实验方法 开展科学研究的能力。

其次针对高年级学生通过分析国内外最新学科发 展与研究前沿, 设置能够促进研究生培养的核心英文课 程。由于知识的客观性, 研究生培养工作在本质上是开 放性的。只有真正掌握理论与实践知识, 才能获得真才 实学, 从而成功应对未来实务中的国际化要求。因此, 在研究生培养中, 一定要努力吸取、获得、转化来自于 无论境内外的优秀 “间接经验”, 这不仅需要国际化的师 资队伍, 更有赖于共享国际优质的教育资源。具体而言, 在课程安排方面, 必须紧跟国内外最新学科发展与研究 前沿, 选用相关领域中典型的原著教材, 尽可能采用英 
文或双语教学模式。在实施方法上，通过慕课或者网络 线上、线下教学, 多方面设置课程学习方式, 以促进研 究生培养的核心课程的国际化水平。使研究生在英文授 课、讨论、作业、考试等环境下, 全面提升国际学术能 力 ${ }^{5}$ 。使研究生在英文授课、讨论、作业、考试等环境 下, 全面提升国际学术能力 ${ }^{6}$ 。

最后, 在完成前两项课程考核的前提下, 鉴于此时 学生外文水平已有一定基础, 建议直接推进学生参与国 外学术活动, 包括参加外国师资直接教学课程, 参与国 际化学术专业讲座, 加入国际化学生交流活动, 以保障 研究生国际化培养工作的即时性与先进性。这需要不断 创造中国学生的国际化交流机会, 以教育交流为纽带, 全面发展研究生教育培养工作的国际化内容, 丰富并探 索各种适应研究生国际化实践能力的社会性活动, 把研 究生国际化培养推向真真正正的实用领域。

\section{2. 构建立体化的国际交流平台}

在研究生国际化培养过程中, 要深刻认识到交流平 台是推进国际化开展的关键载体, 要搭建国际化培养平 台, 首先要建立良好的国际合作关系, 积极拓展合作合 作项目, 寻求优质合作院校 ${ }^{7}$ 。由于不同的国家教育理 念与方式不同, 为了实现实质性国际合作, 要认真研究 合作院校的人才培养方案, 借鉴合作院校的模式, 探索 适合于研究生的国际交流平台。

\section{2. 1. 构建国际学术会议平台}

国际学术会议是各个国家相关学术领域研究者聚 集交流的学术交流形式。国际学术会议不但具有专业性、 学术性的特点, 更具有广泛性及自主性的优势。一方面 高校鼓励学生积极参与国际学术会议, 增加研究生出国 参加国际会议的经费支持力度, 设立专项经费对研究生 参会予以支持。凡收到会议组织方邀请、确定可以参会 者, 到研究生院备案, 参会完毕后报销相关费用。如出 现研究生参加国际学术交流热情较高、实际参会人数较 多的情况, 学校可视情况增加经费投入。另一方面, 高 校定期开设国际学术会议的组织, 如在校内举办圆桌会 议, 国际学术交流会议等。推进教学人员与学生进行充 分的思想交流, 共同互相探讨研究内容方法的可行性。 通过学术研讨互动, 夯实课题理论基础, 促进并提高学 术论文撰写质量和水平。

\section{2. 2. 设置研究生暑期国际学校}

研究生暑期学校作为一种辅助性的教育方式, 在欧 美国家十分流行, 具有办学方向国际化、课程设置多样 化、时间安排灵活、师资队伍水平高、交叉学科深化发 展等特点 ${ }^{6}$ 。研究生暑期学校可以有效实现国际化教育 资源的整合及共享, 提高研究生国际化的培养质量。可 以将暑期国际学院分为两类一类是聘请合作院校的教
授暑期到国内进行授课，另外一类是在暑假期间派送学 生到国际合作学校进行短期的交流学习。

在校内开设暑期国际学校要本着与优势学科紧密 结合、体现学科交叉性的原则。既要体现学科的深厚底 蕴, 又要体现学科的交叉融合, 培养研究生在能力结构 和学术思想上的融合能力。在校内开设的暑期国际学校 不仅对海外教师的职称有要求, 应至少为海外院校副教 授以上, 更对海外教师的学术能力做出要求, 参与暑期 课程的教师具有把握国际前沿的水平，可以开设具有国 际化水准的讲座及课程, 使研究生可以快速与国际化教 师进行交流学习。在暑假期间派送学生到国际合作学校 进行短期的交流学习, 要分体现基础与前沿、系统与特 色相结合的原则。安排团队对国际合作院校进行考查, 国际暑期课程的教学安排要分体现基础与前沿、系统与 特色相结合的原则, 充分考虑到研究生知识结构、研究 方向和外语水平, 重视培养创新思维和学习能力。在暑 假期间派送学生到国际合作学校进行短期的交流学习, “短、平、快” 的使学生体验国际化授课形式, 培养学 生国际化思维。

\section{2. 3. 推动双学位项目促进研究生国际化培 关}

推动研究生国际化培养, 其中最大的难点便在于如 何把培养国际化人才的 “国际化” 这一特点体现出来。 双学位项目涉及两个学校的课程, 如何安排便是一大难 题, 整个课程体系如何设置成为难点。如何保证研究生 在规定时间内完成两个学校的所需学分, 进行更为科学 高效的学习和管理也是需要探索的方面。

在生源选择方面, 双方院校制定共同的标准, 建立 联合招生委员会, 由其负责研究生交流选派任务。制定 境外双学位交换生资格审核的具体规定及流程, 以避免 资格审核过程当中可能出现的漏洞。

在学制方面, 双方学术委员会共同设定教学计划并 且在实施过程中不断修订, 以适应研究生国际的发展的 进步。

在课程方面, 双方院校统一教材和课程资料, 制定 人才培养方案, 每学期互相选派教师进行授课, 在课程 方面保持国内外平衡性。

在学分互认方面, 由双方学术委员会共同制定学分 转换方法, 根据各学校实际情况, 修改双学位交换学生 课程管理规定, 给予交换学生通过多种手段获得相应学 分。比如网络线上学习, 类似课程免除上课直接参加最 终考核等。同时, 进一步扩充互认学分范围, 鼓励研究 生通过境外交流, 境外学位学习等方式, 利用外国课程 学分折抵境内高校的通识类课程, 促进研究阶段的学生 境外交流机会。

鉴于双学位教育背景的知识广阔优势, 参加双学位 培养的研究生往往具备更多知识与能力优势。我们需要 围绕着双学位人才培养项目, 持续推进一系列综合性教 学改革。使得通过双学位学习这种教学方式能够培育应 有的教学成果。最终培养出全新具有充分市场竞争力的 
公共管理类国际型人才。

\section{3. 实施全方位的保障机制}

在高校推进研究生国际化培养的实践过程中, 仅仅 依靠校方是远远不够的, 要逐步建立政府提供政策保障 结合高校构建教育实施平台, 逐步探索实施多方参与、 相互配合、相互补充的三大类保障政策。

\section{3. 1. 完善措施规范等法制化内容建设}

完善措施规范等法制化内容建设, 保证研究生国际 化培养国家战略的有效实施。研究生国际化培养的国家 战略, 是从贯穿顶层设计, 直至一系列配套措施落实完 善。整个阶段若没有法制化的规范措施加以调整, 在实 施过程中或出现问题时则无法真正地进行保障。因此, 推进研究生国际化培养国家战略, 离不开法制化内容的 建设。如何推进法制化建设。

首先, 需要制定并出台一系列相关的规范性文件。 特别要注意, 应积极参考发达国家的相关法制建设经验, 吸取发达国家制度制定时的教训 ${ }^{8}$, 在此基础上, 快速 稳妥的推动我国法制建设实体的成熟落地。其次, 着重 在规范措施彰显教育机会公平性。由于研究生国际化培 养战略基础在于人才的选拔, 因此保障公平公正的接受 教育培养机会至关重要。必须需要站在更高层级, 以制 度化措施, 保障培养机会的均衡与有效, 从而真正选拔 一批真才实学的、有培养价值的人才, 完成培养战略的 实施。最后, 建立健全测评机制的法制化水平, 以可量 化、可操作的规范措施, 真正实现培养战略落实情况的 评估，反哺培养战略的不断升级。

\section{3. 2. 强化师资队伍建设对国际化保障机制 的完善}

工欲善其事必先利其器。要培养具备国际化水平的 研究生群体, 必然要依赖于具有国际化教育水平的高质 量师资队伍。因此, 师资队伍建设问题关系到学生能否 有效培养这一关键问题。强调师资队伍建设。

首先要突出师资队伍的国际化能力建设。这需要开 拓师资力量的国际化培训业务, 定期定岗开展教师的出 国交流与国内合作。其次, 需要建立有效地考评制度, 通过科学的考评手段, 检测师资队伍的国际化教育水平 与育人能力, 建立轮岗或淘汰体系, 不断更新升级师资 队伍的培养力量。最后, 探索师资队伍的可持续自我发 展, 吸纳优秀国际和社会资本, 打通师资人员参与国际 化培养过程中的各种项目通道, 以课题、学术研究等方 式, 推动师资队伍人员的自我学习, 主动升级, 走一条 可持续, 低成本的师资队伍发展道路。

\section{3. 3. 加强系统化监督管理}

系统化监督管理制度的规范化是稳定教学秩序、提 高教学质量的保证 ${ }^{9}$ 。因此, 在推荐研究生国际化的进 程中, 要加强系统化监督管理, 设立国际交流部门, 制 定规章制度, 并且安排专任教师建立学生交流档案, 记 录学生从开始申请交流至返回后跟踪调查结果。质量监 控的措施明确到位, 实现国际化教学管理规范化、制度 化。

\section{5. 结论}

研究生国际化培养是反映高等教育竞争力水平的 关键指标，也是我国从教育大国向教育强国迈进的关键 一步。高校研究生国际化培养从着力培养研究生国际学 术视野、国际学术思维、国际学术交流等国际化能力的 多元内涵出发, 通过改革三层次的课程体系, 建立国际 学术会议、暑期国际学校、双学位交流平台这三类立体 化交流平台，实施全方位的三类保障扶持政策，构筑起 研究生国际化培养体系, 达到 “创新能力强、学术思维 广、国际化能力高”的水平。

\section{项目基金}

本位为首都经济贸易大学研究生教改立 项一般项目《“双一流”建设背景下高校研究 生教育国际化探究》阶段性成果。

\section{REFERENCES}

[1] Education and Teaching Forum,Zhou,XR,Huang,JQ(2014),Research on the innovation of graduate international Training Mode, 2014(49):1-2.

[2] Advances in Social Science, Education and Humanities

Research,Zhang,W,Yuan,X,Zhang,Q(2018), Research on graduate international Education Mode for all staff :(ICHSSR 2018) VOL.213

[3] Inner

Mongolia Education,Wang,XH,Yu,RH,Li,C,(2020),Exploration on the training mode of goal-oriented international vision for graduate students,2020(08):116-118.

[4] Academic Degrees \& Graduate Education.Liu,JS,Xu,MS,Ren,XM.(2015), The construction idea and practice exploration of high-level international courses for graduate students, 2015, (6) :32 -35 . 
[5] 4.AcademicDegrees\&Graduate

Education,Xia,PQ,Jiang,X,Wang,Y(2013). Innovative ideas, based on local, facing the world 2013(10):53-57.

[6] Oil education,Wang,J.(2009), Summer school for Graduate Students from an international perspective2009,

(4): 58-61.

[7] Education

Modernization, Wang,F,Li,CX,Yin,SP,lv,HL,

(2019),Discussion on the internationalization development of Graduate education in China,2019,6(32):95-97+108.

[8] Teaching in Higher Education , Andrea Dlaska(2013), The role of foreign language programmes in internationalising learning and teaching in higher education,2013,18(3):260-271.

[9] Academic Degrees \& Graduate Education,Liu,XL,Zzhang,L,Liu,L, Research on countermeasures to support the construction of "Double First-Class"by internationalization of graduate Education,2016,(4):11-15. 